\title{
Xuất bản sách trong chương trình ISR 2021
}

\author{
Hồ Mạnh Toàn \\ Trung tâm ISR \\ Trường Đại học Phenikaa \\ Ngày 22 tháng 12 năm 2020 \\ http://isr.phenikaa-uni.edu.vn/chitiet/thong-bao 2019222758 66/xuat-ban-sach- \\ trong-chuong-trinh-isr-2021
}

Qua công việc thực tiễn và đánh giá kết quả, Trung tâm ISR nhận thấy cần tiếp tục bổ sung chương trình sản xuất và xuất bản sách, cả trên hệ thống quốc tế lẫn ở trong nước.

Năm 2019, nhằm đảm bảo nhiệm vụ khoa học cấp quốc gia với đề tài NAFOSTED, cuốn sách The Vietnamese Social Sciences at the Fork in the Road đã ra đời, do De Gruyter (Sciendo Imprint) xuất bản và phát hành [1].

Chẳng bao lâu sau đó vài chục thư viện quốc tế đã có lưu trữ (hard copy và điện tử), phục vụ độc giả. Một số cái tên danh tiếng bao gồm: New York University, Rijksuniversiteit Groningen, Universiteitsbibliotheek, Cardiff University, University of Alberta, Koninklijke Bibliotheek, Universiteit van Tilburg Bibliotheek, University of Southampton, National Library of Sweden (LIBRIS), Stockholms universitetsbibliotek, Kungliga Tekniska högskolan, Oklahoma City University Law Library, Delft University of Technology, Deutsche Nationalbibliothek Frankfurt am Main, University of St Andrews, University of Bristol Library, v.v..

Cơ hội được lan tỏa đến người sử dụng chính là mục tiêu trước tiên và trên hết của công việc nghiên cứu và xuất bản học thuật. Trung tâm ISR đã dần củng cố ý thức về giá trị của công việc xuất bản sách quốc tế.

Bên cạnh đó, công việc lưu trữ và quan sát hành vi sử dụng tài liệu xuất bản trong nước cũng giúp nhận ra thêm một số điểm rất đáng lưu tâm. Các cuốn sách đã xuất bản từ trước, nếu như có giá trị lâu bền, sẽ tiếp tục được sử dụng trong đào tạo chính quy các cấp học từ đại học tới tiến sỹ. Giá trị của sách xuất bản trong nước không dừng ở đọc tham khảo và trích dẫn, mà có thể đi thẳng vào chương trình đào tạo.

Vài ví dụ trực tiếp và cụ thể kèm theo. Một số cuốn sách của GĐ Trung tâm ISR xuất bản trong giai đoạn 2007-2009 đã và đang được sử dụng theo cách vừa nêu. Đó là các cuốn

- Văn minh làm giàu \& Nguồn gốc của cải (NXB Chính trị quốc gia, 2007), 
- Các phương pháp toán học trong tài chính (NXB ĐHQG Hà Nội, 2007; đồng tác giả với GS. Nguyễn Văn Hữu—Nguyên Chủ tịch Hội ứng dụng Toán học, thuộc Hội Toán học Việt Nam),

- Kinh tế Việt Nam: Thăng trầm và đột phá (NXB Chính trị quốc gia, 2009; đồng tác giả với GS. Phạm Minh Chính—Hiện đang giữ cương vị Ủy viên Bộ chính trị, Trưởng ban Tổ chức Trung ương Đảng).

Ngoài việc những cuốn sách này được sử dụng và trích dẫn rất nhiều trong luận văn, luận án, báo chí, báo cáo, thì còn được sử dụng trong các chương trình đào tạo chính quy của nhiều trường đại học lớn trong nước, cụ thể là: Trường ĐH Kinh tế quốc dân Hà Nội, Trường ĐH Ngoại thương, Trường ĐH Kinh tế (thuộc Đại học Quốc gia Hà Nội), Trường ĐH Cần thơ, v.v..
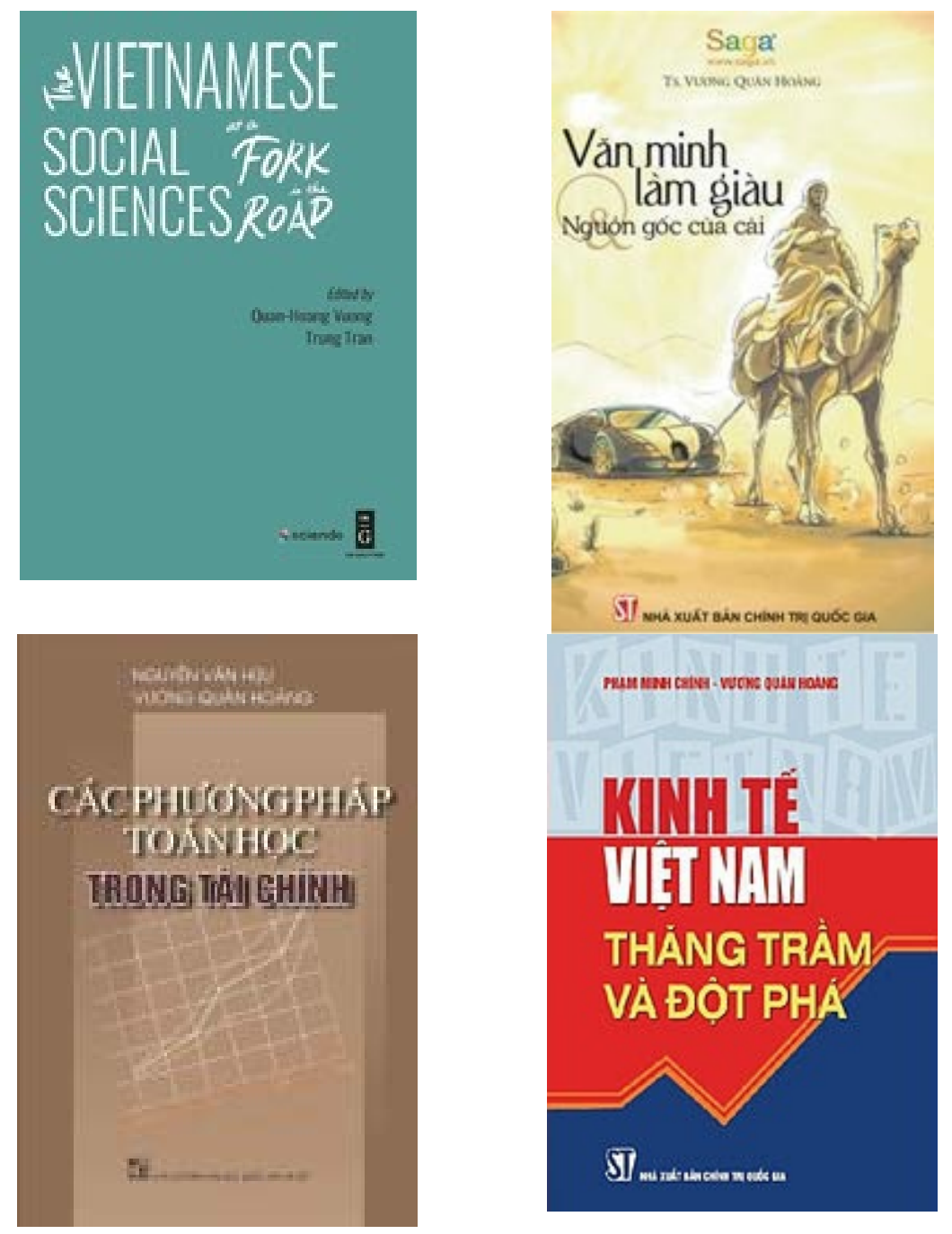
Dựa trên những đánh giá về tính hữu dụng cũng như khả năng lan tỏa của sản phẩm, Trung tâm ISR định hướng tiếp tục phát huy giá trị của việc xuất bản sách cả quốc tế lẫn trong nước kể từ năm 2021, với hy vọng tiếp tục đóng góp những sản phẩm cho văn đàn học thuật.

Tuy đây là một chương trình vất vả và tốn nhiều thời gian, nhưng giá trị củng cố lẫn nhau giữa sách và bài báo hàn lâm rất đáng kể và không thể bỏ qua.

\section{Tài liệu tham khảo:}

[1] Quan-Hoang Vuong, Trung Tran. (2019). The Vietnamese Social Sciences at a Fork in the Road. Warsaw, Poland: De Gruyter (Imprint: Sciendo).

[2] Vương Quân Hoàng. (2007). Văn minh làm giàu \& nguồn gốc của cải. NXB Chính trị quốc gia, Hà Nội.

[3] Nguyễn Văn Hữu, Vương Quân Hoàng. (2007). Các phương pháp toán học trong tài chính. NXB Đại học quốc gia, Hà Nội.

[4] Phạm Minh Chính, Vương Quân Hoàng. (2009). Kinh tế Việt Nam: Thăng trầm và đột phá. NXB Chính trị quốc gia, Hà Nội. 